\title{
Erratum to: Service-Oriented and Cloud Computing
}

\author{
Massimo Villari ${ }^{1}$, Wolf Zimmermann ${ }^{2}$, and Kung-Kiu Lau ${ }^{3}$ \\ 1 Università di Messina, Dip. di Ingegneria Civile, Informatica, Edile, Ambientale, \\ e Matematica Applicata (DICIEAMA), C.Da Di Dio, No.1, 98166 Messina, Italy \\ mvillari@unime.it \\ 2 Martin-Luther-Universität Halle-Wittenberg, Institut für Informatik, \\ V.-Seckendorff-Platz, 06099 Halle (Saale), Germany \\ zimmer@informatik.uni-halle.de \\ 3 The University of Manchester, School of Computer Science, \\ Oxford Road, Manchester, M13 9PL, UK \\ kung-kiu@cs.man.ac.uk
}

\section{Erratum to:}

\section{Villari et al. (Eds.)}

\section{Service-Oriented and Cloud Computing DOI: $10.1007 / 978-3-662-44879-3$}

The book was inadvertently published with an incorrect name of the copyright holder. The name of the copyright holder for this book is: (c) IFIP International Federation for Information Processing. The book has been updated with the changes.

The updated original online version for this book can be found at DOI: $10.1007 / 978-3-662-44879-3$ 